\title{
Inferior Vena Cava Thrombosis: Taking a Second Look at the Inferior Vena Cava in Trauma Patients
}

\author{
Sara Hussain Firas Al Najjar \\ Department of Emergency Medicine, Rashid Hospital Trauma Center, Dubai Health Authority, Dubai, UAE
}

\author{
Keywords \\ Inferior vena cava - Thrombus - Trauma - Emergency · \\ Internal medicine $\cdot$ Radiology $\cdot$ Vascular
}

agement of the thrombus. IVC filters may also be used, but their use may be limited due to anatomical restrictions, as in our case.

(c) 2020 The Author(s).

Published by S. Karger AG, Basel

\begin{abstract}
We present the case of a patient who fell from a 3-m height. He was bought to the emergency department and immediate resuscitative measures were taken. His GCS on presentation was 15 , and the airway was patent and maintainable. Breathing was equal bilaterally, the blood pressure and capillary refill were established to be normal, and a bedside EFAST scan was negative. He was found to have a dislocated left knee, with sensorineural loss distal to the injury. After the dislocation was reduced, a whole-body CT scan was performed and revealed an incidental finding of thrombus in the inferior vena cava (IVC). A thrombus in the IVC by itself is an uncommon complication among trauma patients, but among the cases noted in literature, most patients with an IVC thrombus had a slightly delayed presentation and it was usually discovered a few days after admission. Management of the thrombus depends on the stability of the patient's presentation. When feasible, operative or otherwise invasive procedures can be delayed, allowing for the medical man-
\end{abstract}

karger@karger.com www.karger.com/dmj

Karger $\stackrel{\text { ' }}{5}$

BOPEN ACCESS
(C) 2020 The Author(s)

Published by S. Karger AG, Basel

This article is licensed under the Creative Commons AttributionNonCommercial-NoDerivatives 4.0 International License (CC BY NC-ND) (http://www.karger.com/Services/OpenAccessLicense) Usage and distribution for commercial purposes as well as any distribution of modified material requires written permission.

\section{Introduction}

Inferior vena cava (IVC) thrombosis is a rare complication that can occur in patients who present with trauma to the emergency department. Patients diagnosed with a thrombus in the IVC must be carefully monitored for any complications and signs of clot propagation [1]. When initiating therapy for patients after diagnosis, care should be taken to balance the risk of anticoagulation with the urgent need for immediate therapy.

\section{Case Report/Case Presentation}

A 35-year-old male patient was brought to the emergency department of a trauma center with a history of fall from a 3-m height. No loss of consciousness or vomiting at scene. At the time of presentation, the patient had a 
Table 1. Laboratory results for the patient, drawn immediately upon his presentation to the hospital and $1 \mathrm{~h}$ later

\begin{tabular}{lcc}
\hline & $\begin{array}{l}\text { Normal } \\
\text { range }\end{array}$ & $\begin{array}{l}\text { Patient's } \\
\text { report }\end{array}$ \\
\hline $\begin{array}{l}\text { Immediately upon presentation } \\
\text { Lactic acid }\end{array}$ & $0.5-2.2 \mathrm{mmol} / \mathrm{L}$ & 4.3 \\
Prothrombin time & $11-14 \mathrm{~s}$ & 13.5 \\
Prothrombin time ratio & & 1.00 \\
INR & $0.8-1.1$ & 1.01 \\
RBC & $4.50-5.5010^{6} / \mu \mathrm{L}$ & 4.56 \\
Platelets & $150-41010^{3} / \mu \mathrm{L}$ & 183 \\
\hline I h after presentation & & \\
Prothrombin time & $11-14 \mathrm{~s}$ & 14.5 \\
Prothrombin time ratio & & 1.09 \\
APTT & $28-41 \mathrm{~s}$ & 34.4 \\
INR & $0.8-1.1$ & 1.11 \\
RBC & $4.50-5.5010^{6} / \mu \mathrm{L}$ & 11.8 \\
Platelets & $150-41010^{3} / \mu \mathrm{L}$ & 162 \\
\hline
\end{tabular}

GCS of 15 with a patent airway and had stable vital signs. He was placed on spinal precautions and an E-FAST was performed and was found to be negative. IV lines were placed, and blood was drawn and sent to laboratory for later review, as per local hospital guidelines (Table 1). Primary survey revealed deformity of the left knee with abrasion of the overlying skin. Peripheral pulses in the left lower limb were not palpable, and the patient was noted to have a foot drop and paraesthesia distal to the injury. A Stat X-ray of the knee was performed, and a dislocation of the tibiofemoral joint was noted, with a fracture of the medial tibial plateau (Fig. 1). The dislocation was reduced in the emergency department under procedural sedation, after which the pulses became palpable.

Due to the mechanism of injury and the local polytrauma clinical practice guidelines, a decision was taken to perform a whole-body CT scan. An incidental finding of thrombus was seen in the IVC, $1.5 \mathrm{~cm}$ above the level of the renal veins (Fig. 2). There was no evidence of thrombus in the pulmonary arteries. CT angiography of the lower limbs was performed and did not show any evidence of vascular injury; however, the presence of a comminuted minimally displaced fracture in the posterior aspect of the tibia was confirmed and some lipohemarthrosis was appreciated.

Patient was admitted for further care under the trauma team. The vascular surgery department was consulted, and the decision was taken to not place an IVC filter as

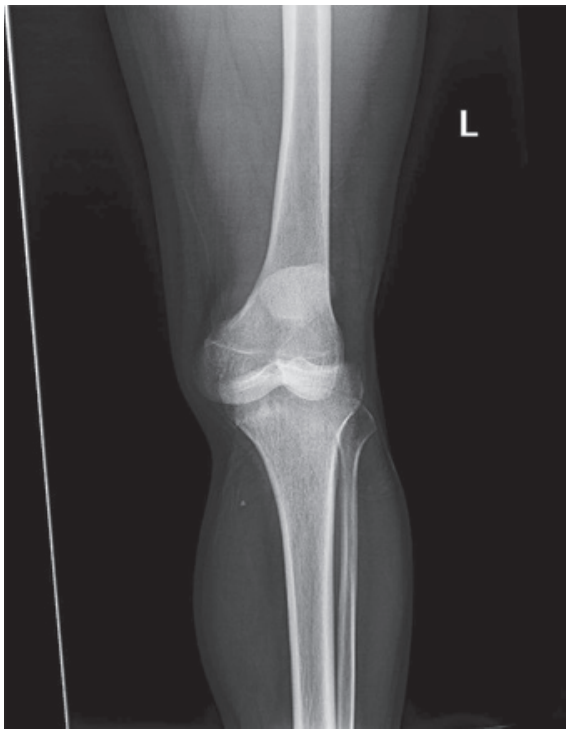

Fig. 1. Dislocated tibiofemoral joint with anterior tibial translation and fracture medial tibial plateau. Proximal tibiofibular joint is well aligned.

the clot was not in a suitable level for insertion. Knee aspiration was performed, and an above knee backslab was applied. The medical department was then consulted, and the patient was started on anticoagulation for 6 months after the necessary thrombophilia workup was completed. Clexane was initiated as per local hospital guidelines, which was later bridged to warfarin after 6 days. An MRI was performed during his hospital stay, which revealed a floating attachment of posterior cruciate ligament with sprain of rest of ligament. The anterior cruciate ligament and body of the medial meniscus were also torn. He was discharged after an uneventful stay in the hospital, to follow up for surgical fixation of the knee in 6 weeks. The patient wanted to complete the rest of his medical treatment in his home country and his oral anticoagulation was monitored as outpatient until he was repatriated. At the time of writing of this paper, he was lost to follow-up.

\section{Discussion/Conclusion}

Post-traumatic IVC thrombus when seen may be an incidental finding and is frequently delayed in presentation after the trauma [1]. Among the noted cases found in literature, very few cases were found with an IVC thrombus that was discovered on the same day of admission, as compared to a delayed onset [1-4]. Mechanisms usually include a retroperitoneal hematoma formation 


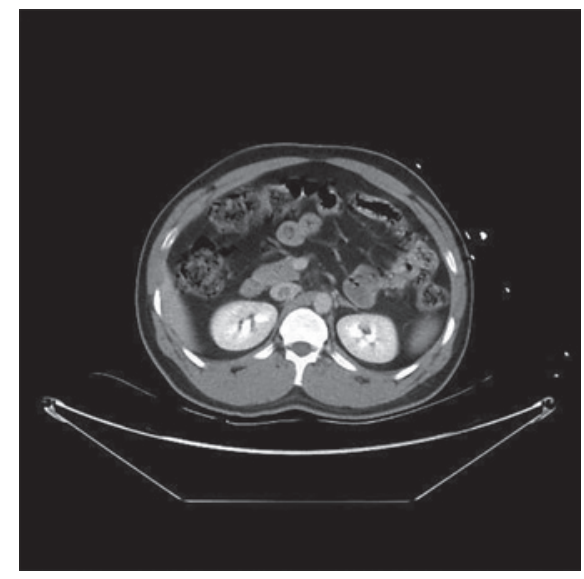

Fig. 2. CT polytrauma with IV contrast showing a persistent filling defect seen in the delayed phase measuring about $4 \times 0.9 \times 0.7 \mathrm{~cm}$ in the inferior vena cava about $1.5 \mathrm{~cm}$ above the level of renal veins.

and subsequent compression. Other possibilities include endothelial damage, as is likely in our case, or hepatic parenchymal injury with venous stasis that extends to the IVC. This already prothrombotic state is then further exacerbated with the hypercoagulability that can occur with trauma: immediately after a trauma, there is a brief period of hypercoagulability, followed by hypocoagulability, which then finally returns to a hypercoagulable state [5]. This mechanism can also be summarized by Virchow's triad of venous thromboembolism: local endothelial damage, along with a stasis of blood flow and a generalized hypercoagulable state that all contribute to a high risk of thrombus formation [5]. The reported mortality rate in these cases is relatively low; Chakroun et al. [1] reviewed all the published literature available regarding IVC thrombus occurrence in post-trauma patients. They found that 4 out of the total 20 cases had died, which include their own patient who had a favorable outcome and 2 of the deaths were directly due to pulmonary embolism. This is also true for non-IVC trauma patients; fatal pulmonary embolism is one of the most common causes of death in patients who survive the first day after a significant trauma [6].

Relevant management of these patients includes a full workup for prothrombotic states. Our patient was screened appropriately through history, examination, and blood investigations for conditions that can increase the likelihood for thrombus formation. The patient's prothrombin time, activated partial thromboplastin time, and INR were all normal immediately upon his presenta- tion to the hospital (Table 1). Screening for specific prothrombotic conditions including nephrotic syndrome was also negative through history, clinical examination, and laboratory tests. It is worthwhile to mention that the authors acknowledge the possibility of limitations due to loss of patient follow-up. While initial blood tests and extensive history taking were unremarkable immediately upon his presentation to the hospital, we were not able to conduct a full thrombophilia screen during his hospital stay to completely rule out rare genetic causes that may present in a similar manner. Ideally, a complete genotypic and phenotypic evaluation would be recommended as outpatient follow-up to confirm the absence of hereditary prothrombotic states. At the time of writing, all attempts to contact the patient for follow-up were unfortunately unsuccessful. Once diagnosed with an IVC thrombus, patients can be managed surgically with an IVC filter. This device is only placed in the infrarenal or suprarenal segments if the patient is at greater risk of morbidity or mortality from the thrombus. In case of overt trauma or damage to the IVC, repair and thrombectomy under extracorporeal circulation are also possible [1]. When feasible, surgical intervention can be postponed; however, if that is not possible, the potential risks of delay must be weighed against the risk of thrombus propagation and resultant complications. In patients who are not eligible for surgical therapy, medical management alone can be considered as an alternative. Post-trauma anticoagulation is recommended to be initiated in an ICU setting in a patient who is not actively bleeding.

\section{Statement of Ethics}

Written consent available.

\section{Conflicts of Interest Statement}

The authors have no conflicts of interest to declare.

\section{Funding Sources}

The authors did not receive any funding.

\section{Author Contributions}

All authors contributed equally to the production of the article. 


\section{References}

1 Chakroun A, Nakhli MS, Kahloul M, Harrathi MA, Naija W. Post traumatic inferior vena cava thrombosis: a case report and review of literature. Int J Surg Case Rep. 2017;36:59-63.

2 Castelli P, Caronno R, Piffaretti G, Tozzi M. Emergency endovascular repair for traumatic injury of the inferior vena cava. Eur J Cardiothorac Surg. 2005 Dec;28(6):906-8.
3 Salloum C, Lim C, Hillion ML, Azoulay D. Reconstruction of the inferior vena cava due to blunt hepatic trauma. J Visc Surg. 2016 Feb; 153(1):75-6.

4 Diab C, Abou Karam A, Laks S, Brunner N. Inferior vena cava thrombus secondary to blunt abdominal trauma. BJR Case Rep. 2017; 3(3):20160117.
5 Gonzalez E, Pieracci FM, Moore EE, Kashuk JL. Coagulation abnormalities in the trauma patient: the role of point-of-care thromboelastography. Semin Thromb Hemost. 2010; 36(7):723-37.

6 O’Malley KF, Ross SE. Pulmonary embolism in major trauma patients. J Trauma. 1990 Jun; 30(6):748-50. 